
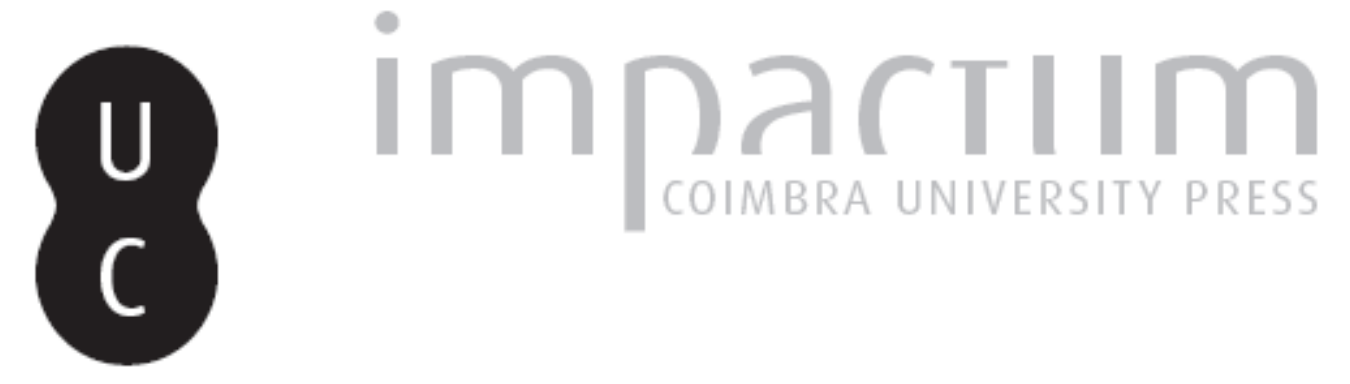

\title{
A charola templária de Tomar: Jerusalém perdida
}

Autor(es): $\quad$ Santos, Carlos Emanuel Sousa

Publicado por: Centro de História da Sociedade e da Cultura

URL persistente:

URI:http://hdl.handle.net/10316.2/39476

DOI:

DOI:http://dx.doi.org/10.14195/1645-2259_11_2

Accessed : $\quad$ 26-Apr-2023 14:12:02

A navegação consulta e descarregamento dos títulos inseridos nas Bibliotecas Digitais UC Digitalis, UC Pombalina e UC Impactum, pressupõem a aceitação plena e sem reservas dos Termos e Condições de Uso destas Bibliotecas Digitais, disponíveis em https://digitalis.uc.pt/pt-pt/termos.

Conforme exposto nos referidos Termos e Condições de Uso, o descarregamento de títulos de acesso restrito requer uma licença válida de autorização devendo o utilizador aceder ao(s) documento(s) a partir de um endereço de IP da instituição detentora da supramencionada licença.

Ao utilizador é apenas permitido o descarregamento para uso pessoal, pelo que o emprego do(s) título(s) descarregado(s) para outro fim, designadamente comercial, carece de autorização do respetivo autor ou editor da obra.

Na medida em que todas as obras da UC Digitalis se encontram protegidas pelo Código do Direito de Autor e Direitos Conexos e demais legislação aplicável, toda a cópia, parcial ou total, deste documento, nos casos em que é legalmente admitida, deverá conter ou fazer-se acompanhar por este aviso.

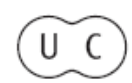




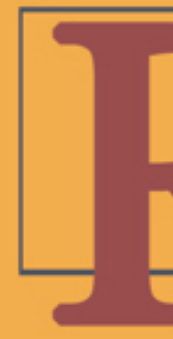

\section{evista de História} da Sociedade e da Cultura

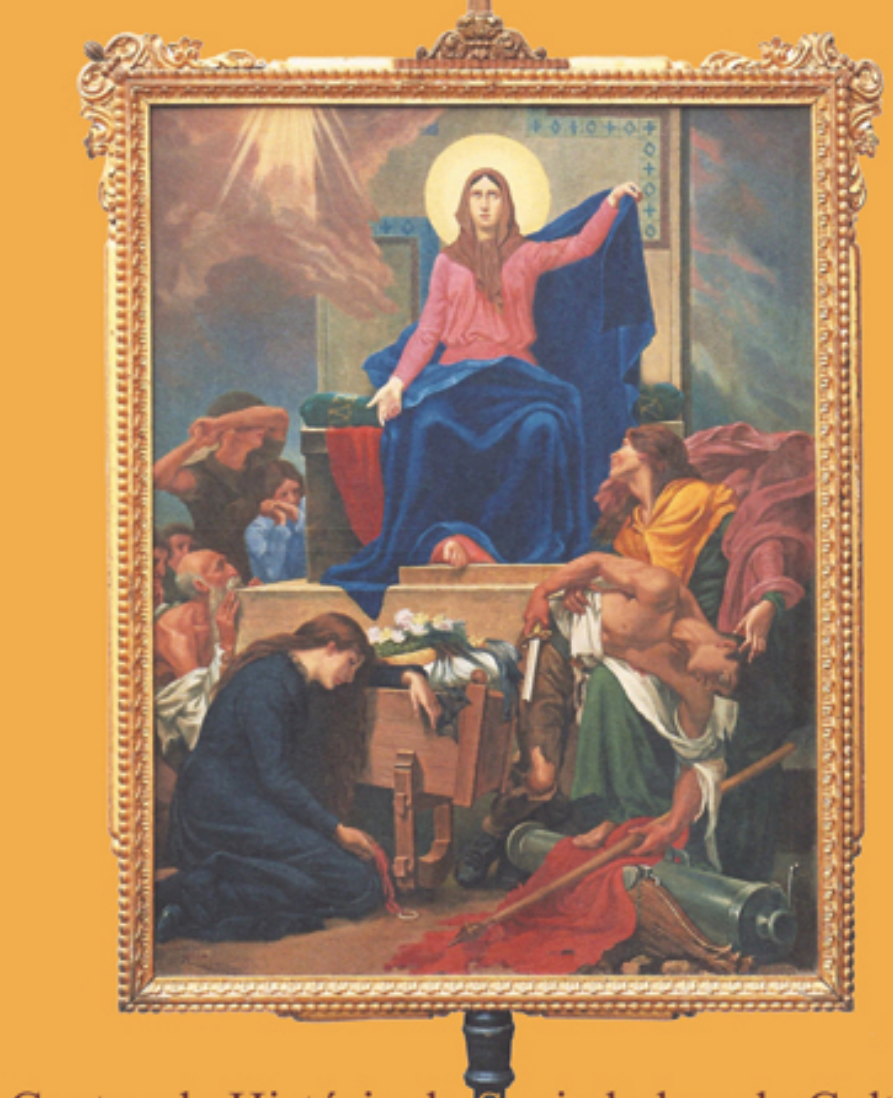

Centro de História da Sociedade e da Cultura Universidade de Coimbra 


\title{
A Charola Templária de Tomar: Jerusalém Perdida*
}

\author{
Carlos Emanuel Sousa Santos \\ Mestre em História da Arte Medieval \\ Doutorando em História da Arte da Idade Moderna \\ Universidade Nova de Lisboa, FCSH \\ carlos.ssantos79@gmail.com
}

Texto recebido em/ Text submitted on: 28/02/2011

Texto aprovado em/ Text approved on: 07/09/2011

\section{Resumo/Abstract:}

A Ordem do Templo** teve as suas raízes no Oriente, com o objectivo de prestar auxílio aos peregrinos que se dirigiam à Cidade Santa, e aos seus respectivos espaços de culto. Portanto, os cavaleiros do Templo entraram em contacto directo com estes lugares e o Santo Sepulcro, Túmulo de Cristo, e a Cúpula do Rochedo foram os mais significativos. Não tardou que realizassem em vários sítios réplicas destas construções, para fazer relembrar estes sagrados monumentos. Ao construir templos que fizessem relembrar os espaços santos de Jerusalém, os crentes escusavam de viajar em peregrinação à Cidade Santa porque estes eram vistos como o próprio túmulo de Cristo, tendo todo o sentido numa Europa "dominada pela fé". Por ser considerado o moimento de Cristo, o Santo Sepulcro foi, variadíssimas vezes, concebido como o centro do mundo durante os séculos XII e XIII e em raros casos no séc. XIV. A cidade de Tomar e a sua Charola acabam por ser um reflexo disso mesmo.

The Order of the Temple $e^{* * *}$ had its origin in the East, with the objective of giving assistance to the pilgrims who headed to the Holy Land and the respective worshipping places. Therefore, the Knights of the Temple had direct access to these places of which the Holy Sepulchre, Jesus' Grave, and the Dome of the Rock were the most significant.

Soon after, reproductions of these constructions were built in many different places, to remind people of these sacred monuments. By reconstructing temples that reminded people of the sacred places of Jerusalem, the faithful did not have the need to make sacred journeys

* Este texto insere-se nos trabalhos de uma dissertação de mestrado em História da Arte Medieval denominado "A Charola Templária de Tomar - uma construção Românica entre o Oriente e o Ocidente" apresentada à Universidade Nova de Lisboa, em 2007. Projecto financiado pela FCT.

** Sobre a Ordem do Templo consultar entre outros, PERNOUD, Régine-Os Templários. [s.1], Publicações Europa-América, 1990;RUNCIMAN, Steven - História das Cruzadas: o reino de Acre e os últimos cruzados. Lisboa: Livros Horizonte, 1995; DEMURGER, Alain - A Grande Aventura dos Templários: da origem ao fim. Lisboa: A Esfera dos Livros, 2006 e FUGUET, Joan - Los Templários en la Península Ibérica. Barcelona: El Cobre Ediciones, 2006.

${ }^{* * *}$ See more about the Order of the Temple in: PERNOUD, Régine - Os Templários. [s.1], Publicações Europa-America, 1990; RUNCIMAN, Steven - História das Cruzadas: o reino de Acre e os últimos cruzados- Lisboa: Livros Horizonte, 1995; DEMURGER, Alain - A Grande Aventura dos Templários: da origem ao fim. Lisboa: A Esfera dos Livros, 2006; Fuguet, Joan - Los Templários En la Península Ibérica. Barcelona: El Cobre Ediciones, 2006. 
to the Holy Land once these were seen as the Holy Sepulchre itself, which made complete sense in a Europe "dominated by faith".

Being considered the moiment of Jesus Christ, the Holy Sepulchre was many times seen as the centre of the world during the XII and XIII centuries and sometimes during the XIV century. The city of Tomar and its Charola are considered to be a reflexion of all this.

Palavras chave/Keywords:

Charola de Tomar; Jerusalém; Santo Sepulcro; Templo de Salomão.

Charola of Tomar; Jerusalem; Holy Sepulchre; Temple of Salomon. 
"Ordenastes-me, construir um templo no teu monte santo e um altar na cidade da tua morada, à imitação da tenda santa que preparaste desde o princípio."

$$
\text { Sb., } 9,8
$$

Partindo de uma contextualização histórica de Jerusalém medieval, podemos perceber as razões de uma possível recriação da Cidade Santa em Tomar ${ }^{1}$ por parte dos irmãos do Templo. Em 1099, os cruzados conquistam Jerusalém, a cidade que acolhia o túmulo de Cristo, naquela que é considerada a primeira cruzada. Doravante teriam de defender com todas as suas forças este estado no Oriente latino (1100). Esta necessidade está na génese das ordens militares, de onde se destaca a Ordem do Templo que teve a sua origem presumivelmente em $1120^{2}$. Segundo o cronista Guilherme de Tiro, nesta altura os companheiros de Hugo de Payns não tinham "nem igreja nem domicílio seguro"3. Então, o rei de Jerusalém Balduíno II alojou-os junto a uma ala do seu palácio, relativamente próximo do Templo do Senhor, segundo escrevem tanto Guilherme de Tiro como Tiago de Vitry.

Logo após a conquista de Jerusalém aos muçulmanos pelos cruzados, todos os monumentos religiosos islâmicos foram "convertidos" ao culto cristão e a Cúpula do Rochedo não foi excepção, passando a ser conhecida como Templum Domini, o Templo do Senhor ${ }^{4}$ [Fig.1 e 2]. Tal situação poderia significar a identificação do edifício como sendo o verdadeiro Templo de Salomão, por parte do cristão. Para além da Cúpula do Rochedo, Jerusalém pautava por um inestimável valor simbólico e espiritual, por ser a cidade que representava a vida e a morte do Filho de Deus: Jesus Cristo. Neste contexto, o Santo Sepulcro e as construções a ele anexadas, nomeadamente o Calvário

1 Referimo-nos neste caso a uma recriação não no sentido que o entendemos hoje mas num contexto histórico muito específico.

2 Fundada em 1118 -1120, em Jerusalém, a Ordem do Templo começou por exercer funções claramente ofensivas. Desta forma, respondia às necessidades da época que não eram mais do que fundir as suas ideias de cavalaria militar com a tentativa de cristianização dos hábitos castrenses que a Igreja estava a tentar levar a cabo.

3 DEMURGER, Alain - A Grande Aventura dos Templários: da origem ao fim. Lisboa: Esfera dos Livros, 200, p. 93.

4 PARROT, André - Le Temple de Jérusalem. Paris: Delechaux e Niestlé S.A., 1954, p. 82 . 
Figura 1

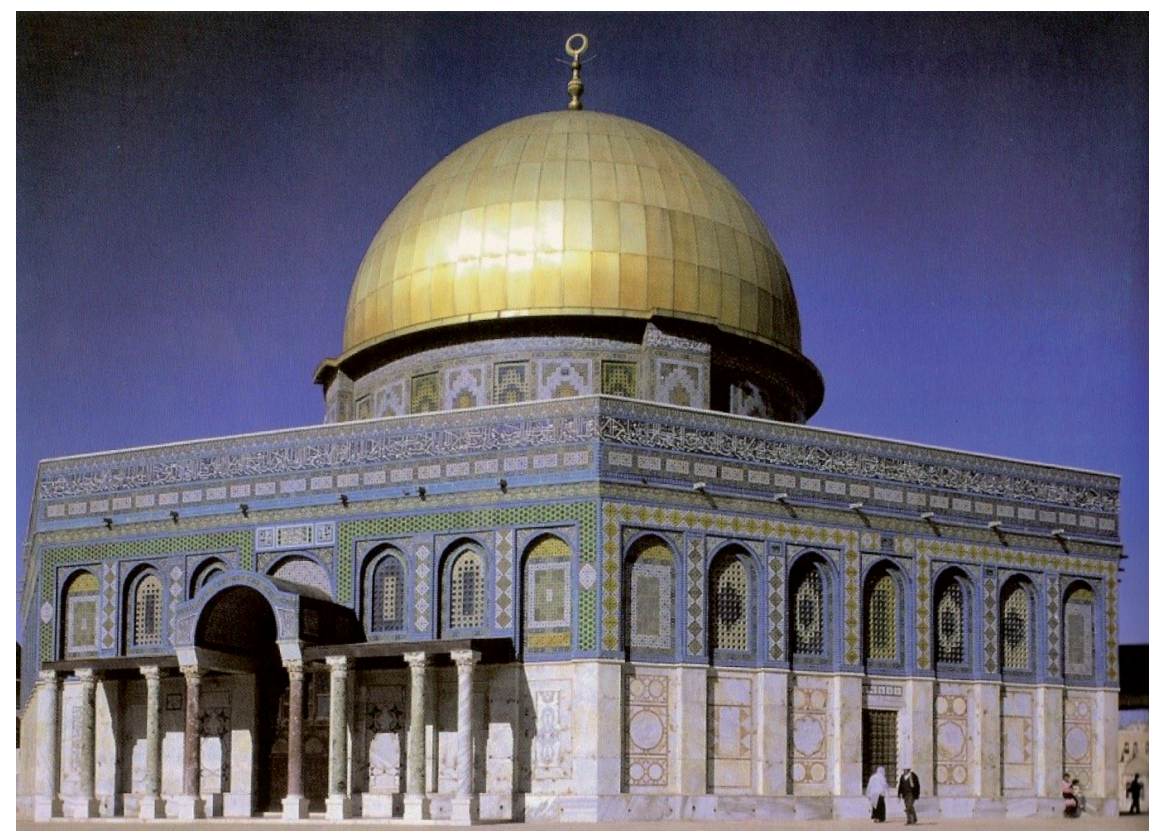

Fonte: Volkmar Enderlein (2004, p. 65). Vista exterior da Cúpula do Rochedo.

Figura 2

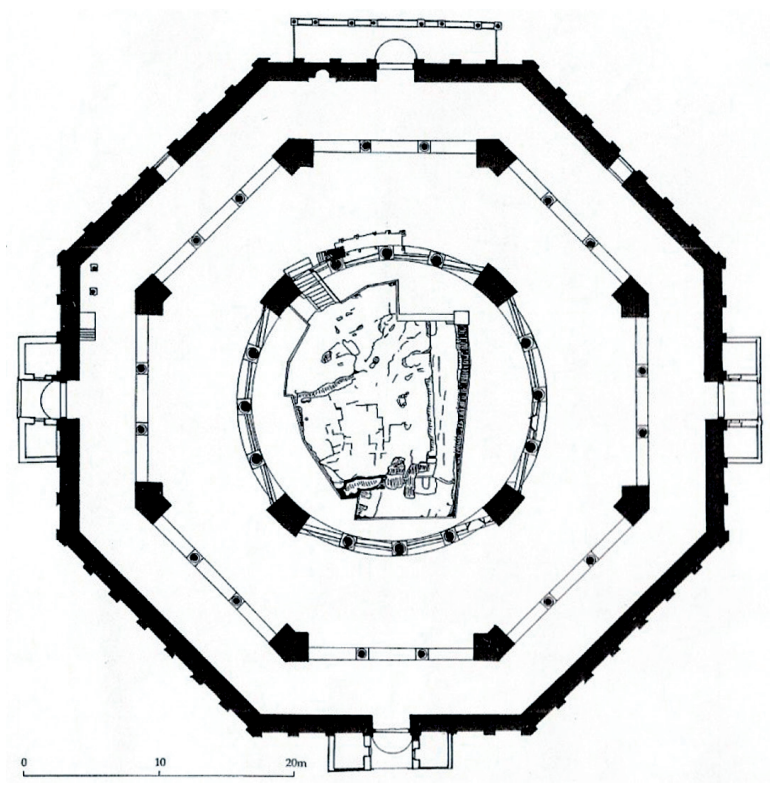

Fonte: Volkmar Enderlein (2004, p. 64). Cúpula do Rochedo (planta). 
e a Cúpula de Santa Helena, que guardava a relíquia da verdadeira Cruz, constituíam o principal pólo de atracção à Cidade Santa [Fig. 3].

Por ser considerado o moimento de Cristo, o Santo Sepulcro foi, variadíssimas vezes, concebido como o centro de Jerusalém e do Mundo. A Cidade Santa também foi representada como centro do Mundo, ou centro geométrico de um mundo circular durante os séculos XII e XIII, e, em raros casos, no século XIV. De facto, e principalmente durante a Idade Média, os artistas, os mecenas, os clérigos e os nobres procuraram construir a imagem do Templo de Salomão, recorrendo desta forma à arte para representar a cidade de Deus: Jerusalém Celeste. Vários autores, entre os quais Rolf Toman, consideram que este facto é de grande relevância na arquitectura, escultura e na pintura, mas, é na arquitectura que encontra maior diversidade de significados. Reforça, ainda, que todas as formas de construção de igrejas - o conjunto formado pelo arco, torre, coluna, abside, abóbada, entre outros - "inspiram-se na cidade do Senhor, uma modificação

Figura 3

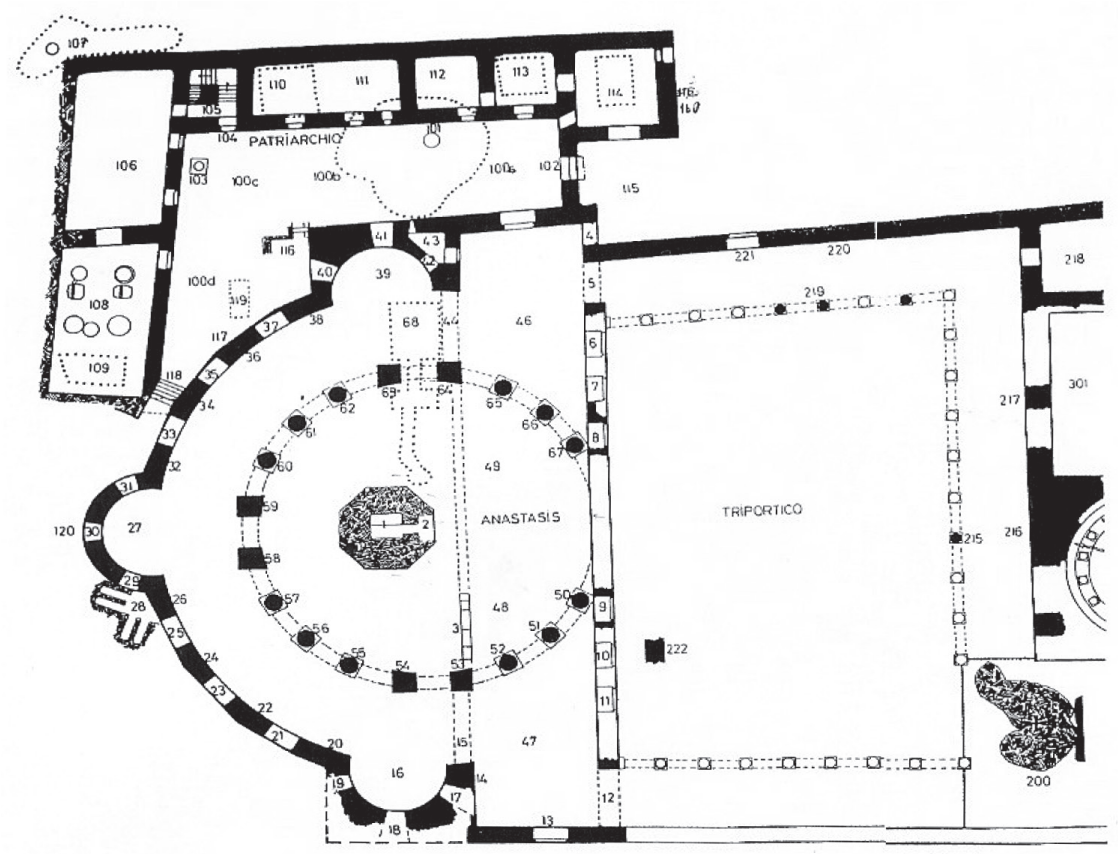

Fonte: Nikolas Jaspert (2005, p. 94). Igreja de Santo Sepulcro de Jerusalém (planta, sécs. IV e XI). 
da antiga concepção da casa de Deus. ". Todo esse significado e "magia" não foram sempre utilizados com rigor. Contudo, a igreja é emblema e símbolo da cidade de Deus, do reino de Deus, a que os crentes ajudam a dar forma. A salvação divina, e o caminho para alcançar a mesma, eram as principais razões que justificavam este tipo de construção.

A cidade conquistada pelo exército ocidental, em 1099, afigurava-se a um paralelepípedo, circundado por muralhas e torres, correspondendo com algumas alterações à actual cidade velha de Jerusalém [Mapa 1]. A urbe medieval - actual cidade velha - estava demarcada por duas vias praticamente perpendiculares que a dividiam em quarteirões. Nela destacavam-se duas colinas; a oeste, o monte do Calvário, lugar santo para os cristãos, devido ao Sepulcro de Cristo, e a leste, o Monte Moriah (também designado de Haram al-Sharif, "casa de Deus" ou ainda "esplanada do Templo", e actualmente "Esplanada das Mesquitas"), lugar sagrado para os judeus e islâmicos ${ }^{6}$ [Mapa 2]. Os primeiros cruzados, quando se apoderaram de Jerusalém, transformaram os edifícios islâmicos do Monte Moriah em igrejas cristãs e reapropriaram-se das tradições judaicas, anteriormente destruídas, por volta de 638, a partir do assalto e domínio muçulmano.

Foi precisamente aqui que se instalaram os irmãos Templários e tinham como principal referência a Cúpula do Rochedo $^{7}$ - onde se destacava a partir deste momento uma grande cruz de ouro, sobre a cúpula ${ }^{8}$ - que, segundo Sílvia Leite, é um imenso relicário, cujo interior, bem no centro, estava reservado a acolher a pedra sagrada que tinha um grande significado para as três grandes religiões que procuravam ter a posse da Cidade Santa.

5 TOMAN, Rolf-O Românico: Arquitectura, Escultura e Pintura. Lisboa: Konemann, 2000, p.14.

6 DEMURGER, Alain - A Grande Aventura..., cit., p. 94.

7 A instalação dos frades Templários no Monte Moriah testemunha, para Demurger, a vontade e os esforços da realeza latina em transformar este sítio no segundo centro de culto cristão da cidade, logo a seguir ao Santo Sepulcro. DEMURGER, Alain - A Grande Aventura..., cit., p. 97.

${ }^{8}$ Em 1142, os freires consagraram a Cúpula do Rochedo como a sua igreja, e reservaram-na para o seu uso próprio. Estava completamente rodeada de muros e dividiram a grande sala de oração do templo em várias celas. Teriam acesso à esplanada através da porta Dourada, uma das sete portas que davam acesso à cidade. Encontrava-se permanentemente fechada excepto no "Domingo de Ramos e no dia da Exaltação da Santa Cruz". AMARANTE, Eduardo - Templários: de Milícia Cristã a Sociedade Secreta. Lisboa: Publicidade Quipu, 2001, Vol. II, p. 36-37. 


\section{Mapa 1}

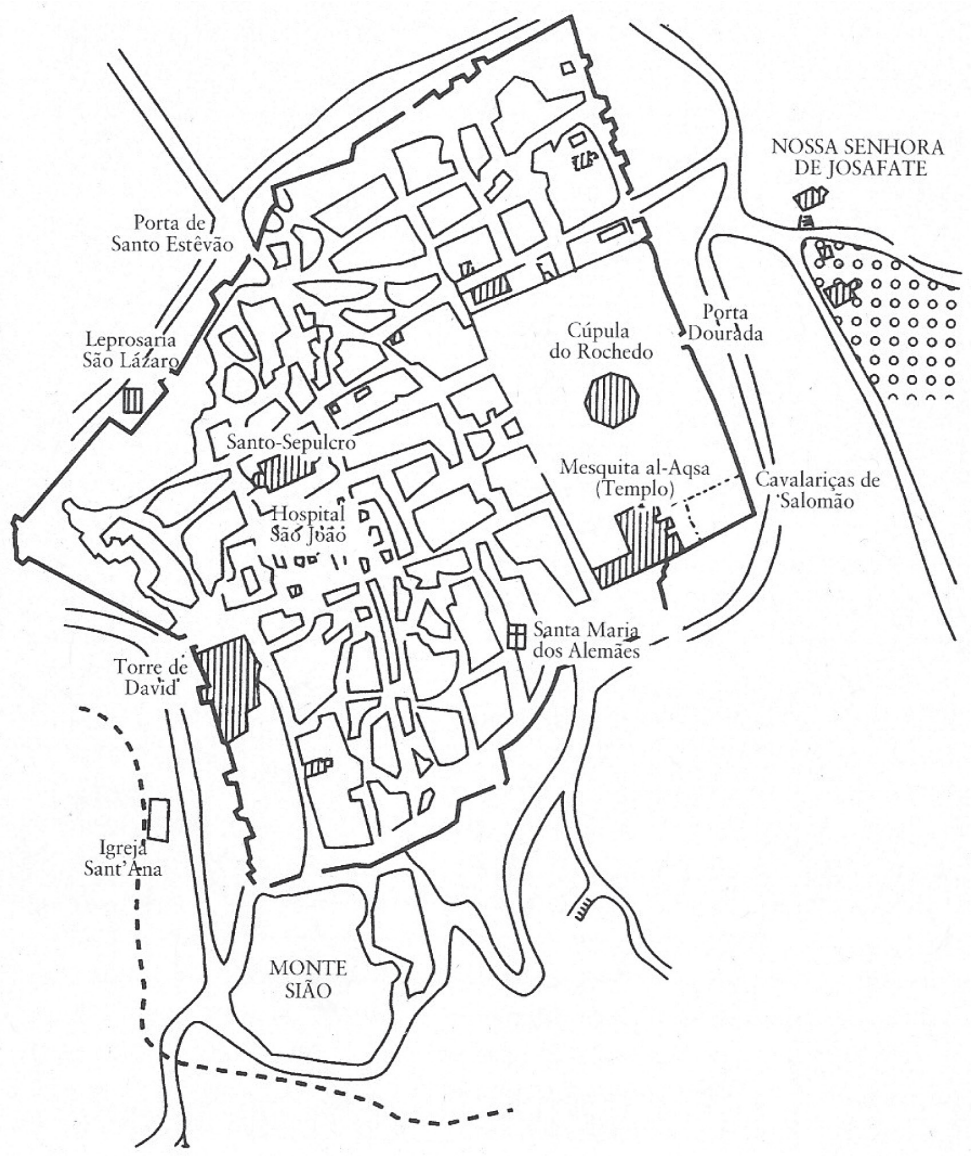

Fonte: Alain Demurger (2005, p. 627). Mapa de Jerusalém no tempo das Cruzadas.

Para o cristianismo, este recinto erguido nas ruínas do Templo de Salomão continha no centro, a pedra onde Abraão ofertara o filho Isaac ao seu Deus, herança que é partilhada igualmente pelo judaísmo e islamismo. Ainda, para os muçulmanos trata-se da pedra onde o profeta Maomé ascendera aos céus e para o judeus e cristãos a rocha divina servira de suporte à Arca da Aliança e de cabeceira dos sonhos de Jacob? .

9 LEITE, Sílvia - Tomar e a nova Jerusalém - a Charola do Convento de Cristo e o Templo de Salomão. Património Estudos. Lisboa: IPPAR, No 4, 2003, p. 157. 
Mapa 2

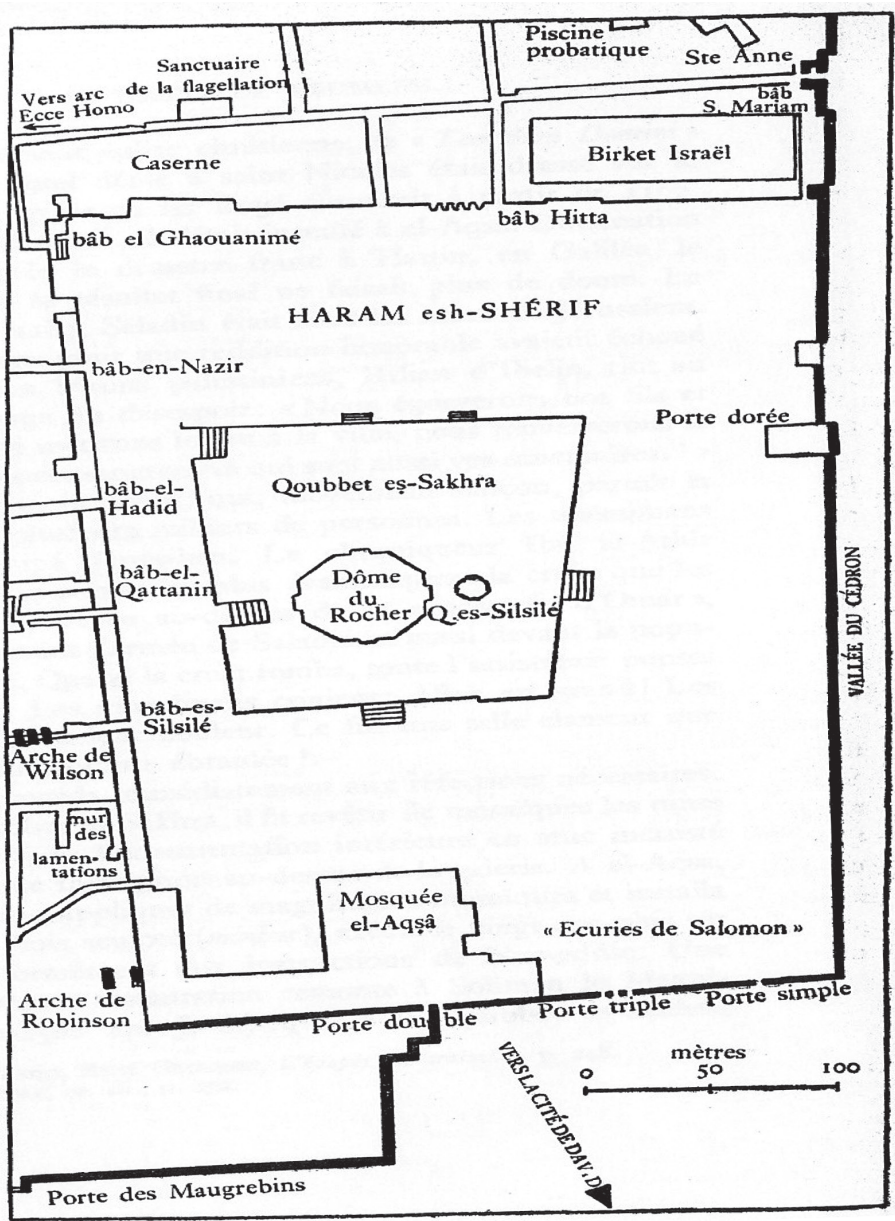

Fonte: André Parrot (1954, p. 80). Plano da Esplanada do Templo (Jerusalém).

Logo que Saladino recuperou a cidade de Jerusalém em 1187, ordenou que fossem destruídos todos os edifícios anexos construídos pelos Templários junto a al-Aqsa e restaurou o seu estado original, bem como os outros espaços até aí convertidos ao culto cristão ${ }^{10}$. Os Templários saídos deste ambiente de profunda nostalgia, principalmente depois da sua perda, vivido na

${ }^{10}$ DEMURGER, Alain - A Grande Aventura..., cit., p. 97. Os cristãos voltaram a reconquistar a cidade em 1229, através de investidas dirigidas por Frederico II, mas foi durante pouco tempo, já que, em 1244, Jerusalém passa novamente para as mãos dos inimigos. 
Terra Santa, quiseram reproduzi-lo na sua sede em Portugal, ou seja transformar Tomar no Umbigo do Mundo, no Centro do Universo. Como tal, os irmãos procuraram seguir os princípios arquitectónicos ou as suas respectivas variações implantadas nestes lugares, alcançando uma geografia intelectual e espiritual ${ }^{11}$ que transpôs fronteiras, expandindo-se por toda a Europa. Desta forma, pode-se explicar a existência de várias tentativas de construir à imagem da Cidade Santa de Jerusalém trazida pelos cruzados, em Tomar.

Com efeito, não é de estranhar que D. Gualdim Pais ${ }^{12}$ tenha feito edificar monumentos que apontassem claramente um referente mítico, imitando a imagem do Santo Sepulcro de Jerusalém ou da Cúpula do Rochedo, ambos templos de planta centrada. Convém esclarecer que, uma "cópia" ou "imitação" arquitectónica funcionava sempre de um modo muito vago no quadro da representação medieval, chegando a encontrar construções bastantes diferentes, mas com significados similares, e outros praticamente idênticos, contudo, com funções distintas. A dita "cópia", observa Paulo Pereira, não passava, portanto, de um jogo onde se procurava aproximar uma ou mais características fundamentais do edifício-modelo ${ }^{13} \mathrm{e}$ em Tomar encontramo-lo certamente na sua planta centralizada. Deste modo, transpunham-se as barreiras geográficas, económicas e culturais com a construção de um templo que evocasse outro, mesmo com uma distância considerável a separá-los. Ao construir a Charola ${ }^{14}$, os Templários tinham

${ }^{11}$ LACERDA, Aarão de - História da Arte em Portugal. Porto: Portucalense Editora, 1942 , p. 358.

12 Sobre o Mestre D. Gualdim Pais ver entre outros, GUIMARÃES, Vieira-A Ordem de Cristo. Lisboa: Edição de autor, 1941; FRANÇA, José Augusto - Tomar. Lisboa: Editorial Presença, $1^{a}$ ed., 1994; MATTOSO, José - Ricos-homens, infanções e cavaleiros: a nobreza medieval portuguesa nos sécs. XI e XII. Lisboa: Guimarães Editores, $3^{\mathrm{a}}$ ed., 1998; BARROCA, Mário - Epigrafia Medieval Portuguesa (862-1422). Lisboa: Fundação Calouste Gulbenkian, 2000; e VALENTE, José - Soldiers and Settlers: the Knigths Templars in Portugal, 1128-1319 , tese de doutoramento apresentada à Universidade da Califórnia. Santa Barbara, 2002.

${ }^{13}$ PEREIRA, Paulo - Enigmas. Lugares Mágicos de Portugal: Templários e Templarismo. Lisboa: Círculo de Leitores, 2005, p. 190.

${ }^{14}$ A Charola templária de Tomar foi, com o tempo, muito transformada, apresentando um aspecto bastante diferente daquele que vemos na iluminura manuelina, dos inícios de quinhentos. Estamos na presença de uma construção pétrea com um plano circular concêntrico, com um núcleo central oitavado e um deambulatório poligonal de 16 lados, começado a edificar nos finais do século XII. Este edifício é considerado, sem qualquer equívoco, como 
como objectivo simbólico a realização da chamada "viagem ao centro" ou “orientação espiritual”, conseguindo assim atingir "uma vitória sobre o espaço e sobre o tempo, visto que o seu objectivo se identifica ritualmente com o Objectivo supremo, com o centro supremo, (...) com a Jerusalém celeste e a Igreja"15.

Desta forma, pode-se aludir que a charola templária tenta representar os dois principais edifícios de Jerusalém medieval: o Templo de Salomão, que não é mais do que o reflexo da Cúpula do Rochedo e o Santo Sepulcro. Assim, podemos afirmar que estamos na presença de um exemplo curioso de fusão numa única construção de várias imagens míticas, aliás, muito comum durante o período medievo. No entender de Juan Ramirez, esta situação pode explicar as afinidades entre o núcleo principal da igreja de Vera Cruz de Segóvia ${ }^{16}$, e a Mesquita de Jerusalém, que sobrepõe uma

sendo uma das grandes obras medievais, a nível europeu, arquitectada pelos Templários, não só pelos seus elementos constituintes, como também pelo seu estado de conservação e principalmente devido às soluções do seu acompanhamento e verticalidade e ainda à sua sugestiva espacialidade interior. ALMEIDA, Carlos Alberto Ferreira de - História da Arte em Portugal: O Românico. Lisboa: Editora Presença, 2001, p. 138. No que concerne ao plano iconográfico e escultórico da charola, podemos admirar capitéis historiados, geométricos ou com motivos vegetalistas, que seguem de perto os de Coimbra, não só pelos temas tratados, mas também pelo estilo e feitura. Deste conjunto diversificado de temas historiados temos a destacar, contudo, um. Trata-se de um capitel que retrata presumivelmente a cena bíblica de Daniel na cova dos leões, porque estes encontram-se domados. Apresenta um homem de expressão rigorosa, com olhos bem abertos e fixos, panejamentos realizados com muita destreza, que ocupa o espaço intermédio. Enquanto que a mão esquerda desta figura pousa sobre o joelho, a outra descansa sobre um dos leões que o envolve. Esta cena acaba por ocupar praticamente todo o cesto do capitel, sendo que as partes vagas são preenchidas com motivos florais. É curioso verificar que um dos leões é mantido no espaço correspondente por uma grande folha que passa caprichosamente pelo seu pescoço e por um ramo que percorre o seu corpo. A mesma situação verifica-se num capitel da nave lateral sul da Sé Velha de Coimbra, sendo que neste caso, o leão é substituído por um cão com cabeça de homem.

${ }^{15}$ HANI, Jean - O Simbolismo do Templo Cristão. Lisboa: Edições 70, 1981, p. 99.

${ }^{16}$ A igreja de Vera Cruz de Segóvia encontra-se próxima das construções fortaleza orientais ou do Templo de Paris, casa-mãe da Ordem do Templo, e é constituída por duas partes que decompõem a igreja poligonal, o que faz com que haja compatibilidade entre as paredes interiores e exteriores, e três absides orientadas a leste, bem como um grande portal com aspecto de um "funil" a ocidente, o que transforma o espaço ao mesmo tempo numa planta central e longitudinal. RINCÓN-GARCIA, Wifredo - Aspectos artísticos de la Orden del Santo Sepulcro en España in Ordens Militares: guerra, religião, poder e cultura, Actas do III Encontro sobre Ordens Militares. Lisboa: Edições Colibri, Câmara Municipal de Palmela, Vol. II, 1999, p. 421. 
planta central com três edículas que relembra a forma como se relacionam a Anástasis, e o edifício basilical no Santo Sepulcro ${ }^{17}$.

Convirá, de seguida, esclarecer onde e como podemos "descodificar" esta possibilidade de fusão de imagens na Charola [Fig. 4 e 5]. Relativamente ao Santo Sepulcro, estas imagens estão na sua planta circular e nos seus respectivos anéis concêntricos, nomeadamente, o deambulatório e a rotunda central. Em primeiro lugar, a planta deste edifício sendo circular, evoca, o universo e a vida eterna, isto é, a vinda de Cristo depois da ressurreição, aproximando-se deste modo, de Jerusalém. Em segundo lugar, a Anástasis é aqui simbolizada pelo grande núcleo central, envolve o que teria sido o Túmulo de Cristo - o Martyrium - constituido por 8 pilares, número que evoca a ressurreição. Pelo que foi dito, é crível que, o Mestre D. Gualdim Pais procurou na arquitectura recriar a cidade ideal na sede dos templários em Portugal: Tomar.

Figura 4

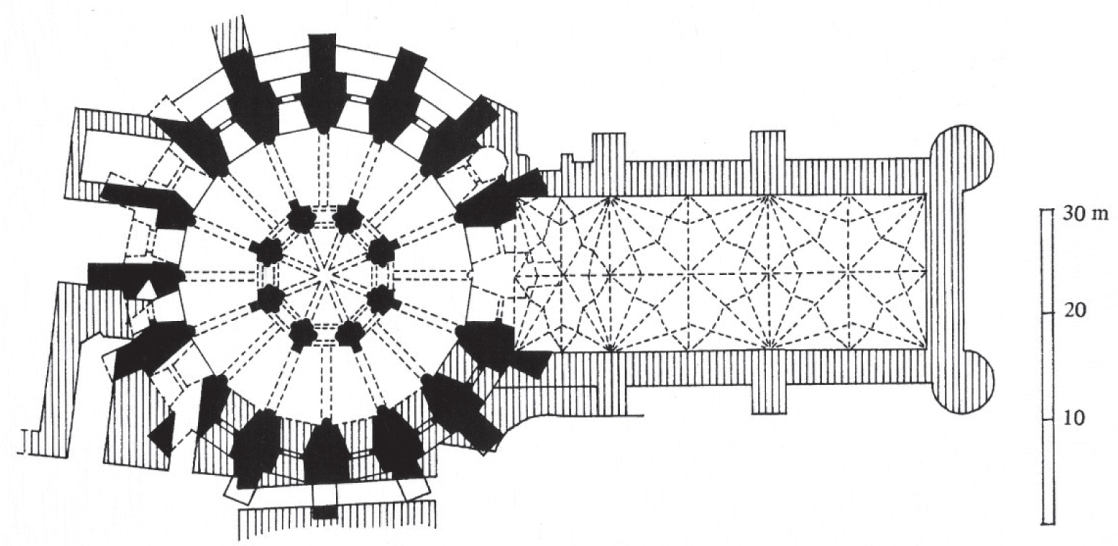

Fonte: Paulo Pereira (2003, p. 12). Planta da rotunda de Tomar (séc. XII-XIII) e do coro Manuelino (séc. XVI).

Já a Cúpula do Rochedo é representada na charola de Tomar não apenas pela sua estrutura em rotunda, como também pelo facto do edifício da Ordem do Templo estar erigido sobre uma plataforma rochosa, circunstância que assume uma intenção clara em simbolizar a "pedra sagrada" que se

\footnotetext{
${ }^{17}$ RAMIREZ, Juan Antonio - Dios Arquitecto. Madrid: Ediciones Sinela, 1995, p. 10.
} 
Figura 5

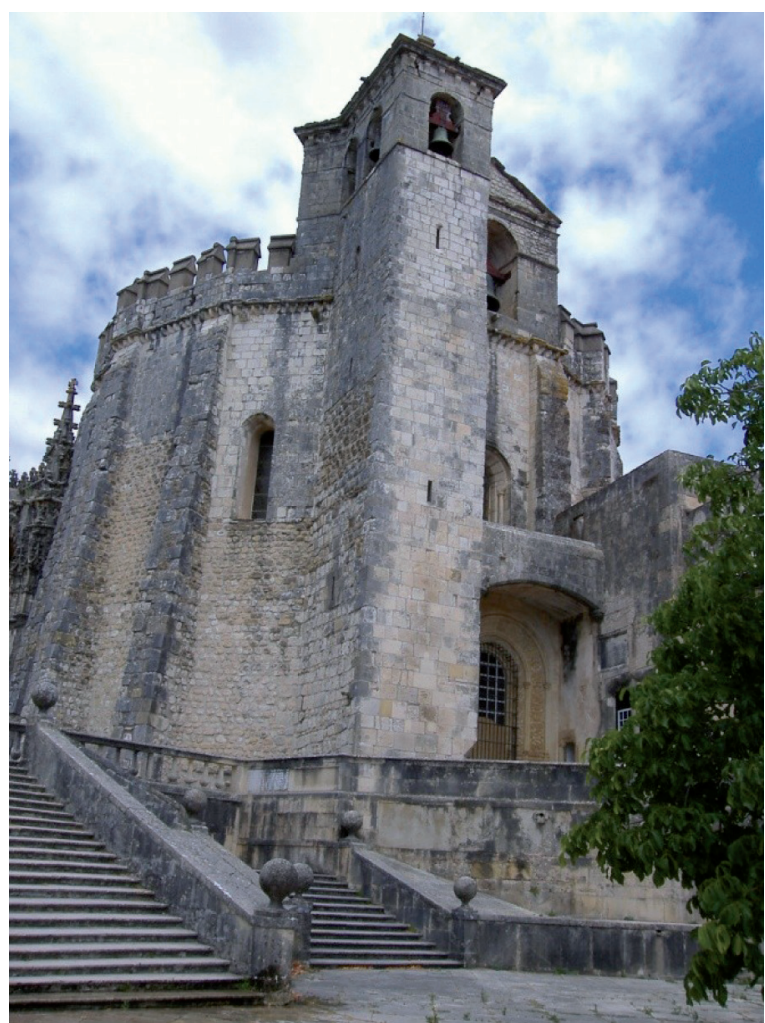

Foto do autor. Vista exterior da Charola de Tomar.

encontra no centro da Mesquita de Jerusalém, protegida pela sua grande cúpula [Fig. 6].

Para albergar esta "rocha sagrada" foi concebida uma construção octogonal, símbolo do universo que estabelecia o contacto entre o céu e a terra, através da escada celeste - símbolo por excelência de ascensão e valorização - representada nos sonhos de Jacob que a caminho da Mesopotâmia "serviu-se de uma das pedras do lugar como travesseiro e deitou-se" (Gn., 28, 11). Esta pedra passa a figurar-se como o centro do mundo segundo a análise dos textos sagrados quando fala da "escada dos anjos". Jean Hani vê nesta escada o "eixo do mundo" cuja parte inferior repousa na Terra e cujo topo constitui a "porta do céu", e é o caminho natural dos anjos como "mensageiros" do Céu na Terra e executores das vontades 
Figura 6

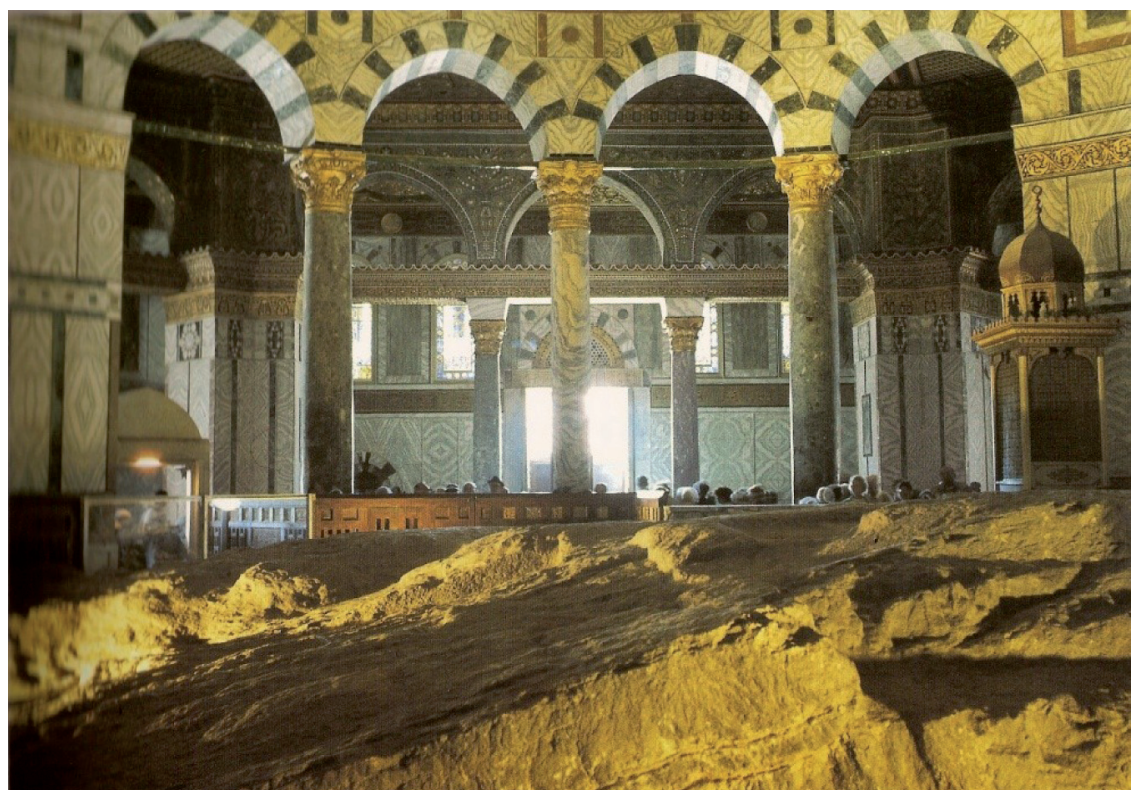

Fonte: Oleg Grabar (2004, p. 43). Pormenor da pedra sagrada no interior da Cúpula do Rochedo (Jerusalém).

celestes ${ }^{18}$. O Mestre D. Gualdim Pais tentou reportar esta imagem da pedra de Jacob e toda a sua simbólica para Tomar, construindo a sua igreja sobre uma rocha e encimada por uma cúpula celeste, sendo venerada por Judeus, Cristãos e Muçulmanos, alcançando a Cidade Santa de Jerusalém ${ }^{19}$.

A Charola, edificada de forma circular, possibilitava uma adoração e oração circundante incorruptível à volta da pedra de incalculável valor simbólico e era um "perystillo do Paraíso, onde sobre os mysticos, os inspirados desciam as graças celestes", que os Templários, "com a sua bênção espargiam por todos os circunstantes, as recebiam cheios de fé" ${ }^{\prime 2}$. Paulo Pereira avança que a identificação do oratório-fortaleza com Jerusalém e o Templo de Salomão é particularmente acentuada na iconografia

${ }^{18}$ HANI, Jean - O Simbolismo..., cit., p. 108.

${ }^{19}$ GANDRA, Manuel J. - Da Vida, da Morte e do Além: aspectos do sagrado na região de Mafra. Mafra: Câmara Municipal de Mafra, Elo-Publicidade, 1996, p. 30.

${ }^{20}$ SOUSA J. M. Cordeiro de - Obras no Convento, in Anais da U.A.M.O.C. Lisboa: Imprensa Lucas, 1943, p. 98. 
quinhentista e seiscentista, já no tempo do rei Venturoso, quando se verifica uma acepção "salomónica" do simbolismo arquitectónico" que poderia na altura estar bem mais viva que na época românica ${ }^{21}$.

Entretanto, segundo vários investigadores, não é só na rotunda dos Templários que encontramos paralelismos com Jerusalém. Estão a referir-se concretamente ao complexo militar e à própria cidade de Tomar. É de conhecimento de todos, que as representações do espaço urbano de Jerusalém assumiam na Idade Média sentidos, segundo Nuno Oliveira, “ (...) ligadas ao espiritual e a material, numa idealização complexa onde convergem a cidade transcendente (futura, atemporal e omnitemporal) e a cidade real (passada, actual e messiânica)". O autor citado aponta que esta síntese visual se fundamenta nas passagens do Apocalipse e na tradição cristã, nomeadamente a partir das obras de Santo Agostinho e São Jerónimo ${ }^{22}$. Na cidade santa que o Mestre D. Gualdim Pais conheceu destacavam-se quatro espaços: a grande "esplanada do Templo", a leste, com Cúpula do Rochedo e a Mesquita-al-Aqsa (casa mãe dos Templários); o Santo Sepulcro e a Torre de David a oeste.

Se compararmos esta cidade velha com o castelo de Tomar templário constatamos algumas analogias entre elas duas, nomeadamente pelo número de subdivisões, ou seja, quatro: a rotunda, e a cidadela com a sua torre de menagem - que "substituem" a Cúpula do Rochedo e a Mesquita-al-Aqsa, localizadas na Esplanada do Templo ou o Monte Moriah-; a porta do Sangue e a igreja de Santa Maria do Castelo, que representam a Torre de David e o Santo Sepulcro, respectivamente. Segundo Nuno Oliveira, tal como a abadia de Claraval, a idealização do castelo templário passava pelo ascetismo de fortificação e mosteiro, baseada na transposição simbólica de Jerusalém, terrestre e celeste ${ }^{23}$. A arte templária em Portugal parece estar relacionada com os modelos espiritualizados, sobretudo associados à presença do Templo

${ }^{21}$ PEREIRA, Paulo - A obra Silvestre e a Esfera dos Reis, Iconologia da Arquitectura Manuelina na Grande Estremadura. Coimbra: Instituto de História da Arte, FCUL, 1990, p. 123.

${ }^{22}$ OLIVEIRA, Nuno Villamariz - Os Castelos da Ordem do Templo em Portugal 1120 - 1314, 2 vols., Tese de mestrado de História da Arte apresentado à Universidade Nova de Lisboa, Lisboa, 2000, p. 215.

${ }^{23}$ OLIVEIRA, Nuno Villamariz - Os Castelos da Ordem... cit., p. 184. 
na Cidade Santa, ou seja, estamos perante uma tentativa em restaurar um espaço sagrado, à imagem daquela que se estava a dissolver em Jerusalém.

É curioso também verificar que nos desenhos de Jerusalém celeste - como são os exemplos dos planos medievais de St. Bertin (?), da Biblioteca de Haia (cerca de 1170/1180), e de Roberto o Monge (séc. XI) - a imagem do Templo de Salomão parece destacada, num ângulo superior e ligeiramente centrado, assumindo uma orientação bastante vertical [Mapa 3 e 4]. Ora, em Tomar, o elemento que mais respeita esta aparência é claramente a charola, isto é,

Mapa 3

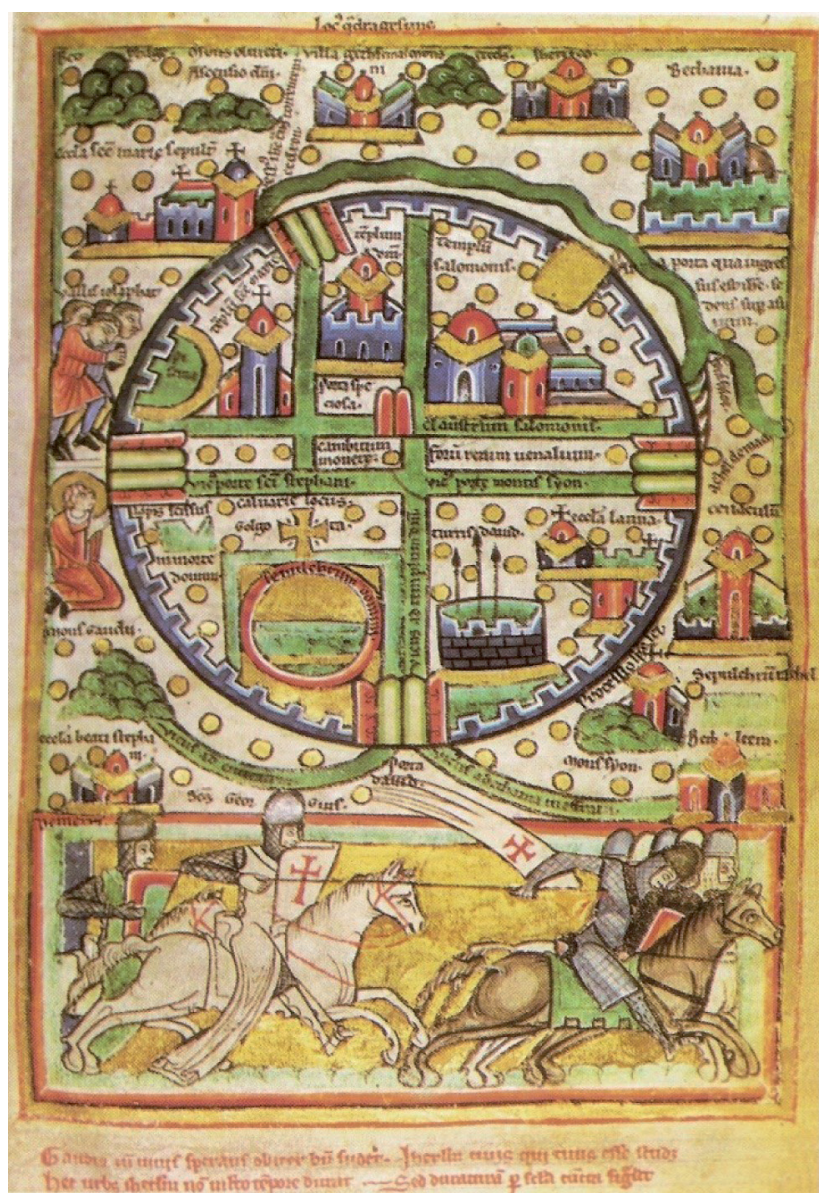

Fonte: Rolf Toman (2000, p. 14). Mapa de Jerusalém medieval de St. Bertin, Biblioteca de Haia (c. 1170/1180). 


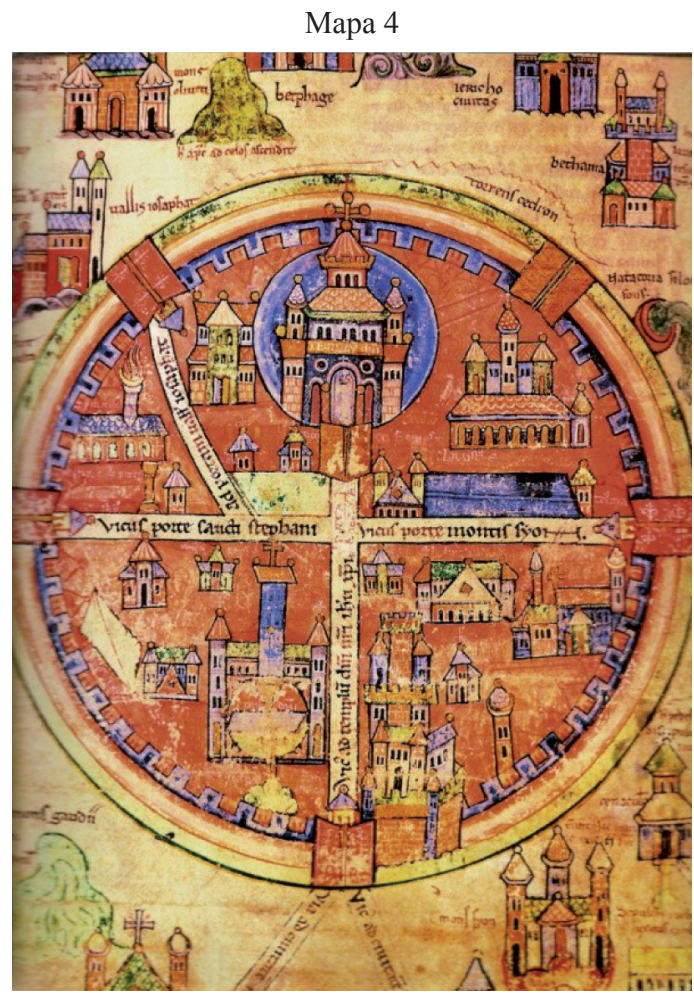

Fonte: Nikolas Jaspert (2005, p. 81). Plano da cidade medieval de Jerusalém, na crónica das Cruzadas, de Roberto, o monge (séc. XI).

estamos mais uma vez perante uma tentativa forte de aproximar o castelo e a sua igreja da cidade santa. Nuno Oliveira alerta para o facto de observar nestas duas urbes uma afinidade manifesta nos seus traçados viários. As vias da porta de Santo Estêvão e da porta de Sião, em Jerusalém, parecem estar igualmente reproduzidas no castelo de Tomar, respectivamente através da passagem que conduz da porta do Sol à Charola e do caminho que ligava a porta do Sangue a um outro acesso a norte, através dos paços henriquinos ${ }^{24}$.

${ }^{24}$ Para Nuno Oliveira, existe ainda a possibilidade de que as muralhas setentrionais e ocidentais de Tomar tenham tido um perfil aproximadamente rectilíneo, como acontece com aquelas que rodeiam o Monte do Templo, em Jerusalém. OLIVEIRA, Nuno Villamariz Os Castelos da Ordem ... cit., p. 216. 
Relativamente à urbe de Tomar, no século XII, Manuel Gandra vê nela uma tentativa de transformá-la numa nova Jerusalém, isto é, uma duplicação da Santa Cidade. Para isso, D. Gualdim Pais traçou uma circunferência que tinha como centro a igreja de S. João Baptista, calculando o raio $(380 \mathrm{~m}) \mathrm{de}$ modo que esta passasse sobre o local assinalado pela tradição conforme o martírio de Santa Iria e igualmente pela rotunda templária, S. Gregório e a capela de Santa Bárbara (hoje desaparecida), localizada a oeste do castelo ${ }^{25}$ [Mapa 5].

\section{Mapa 5}

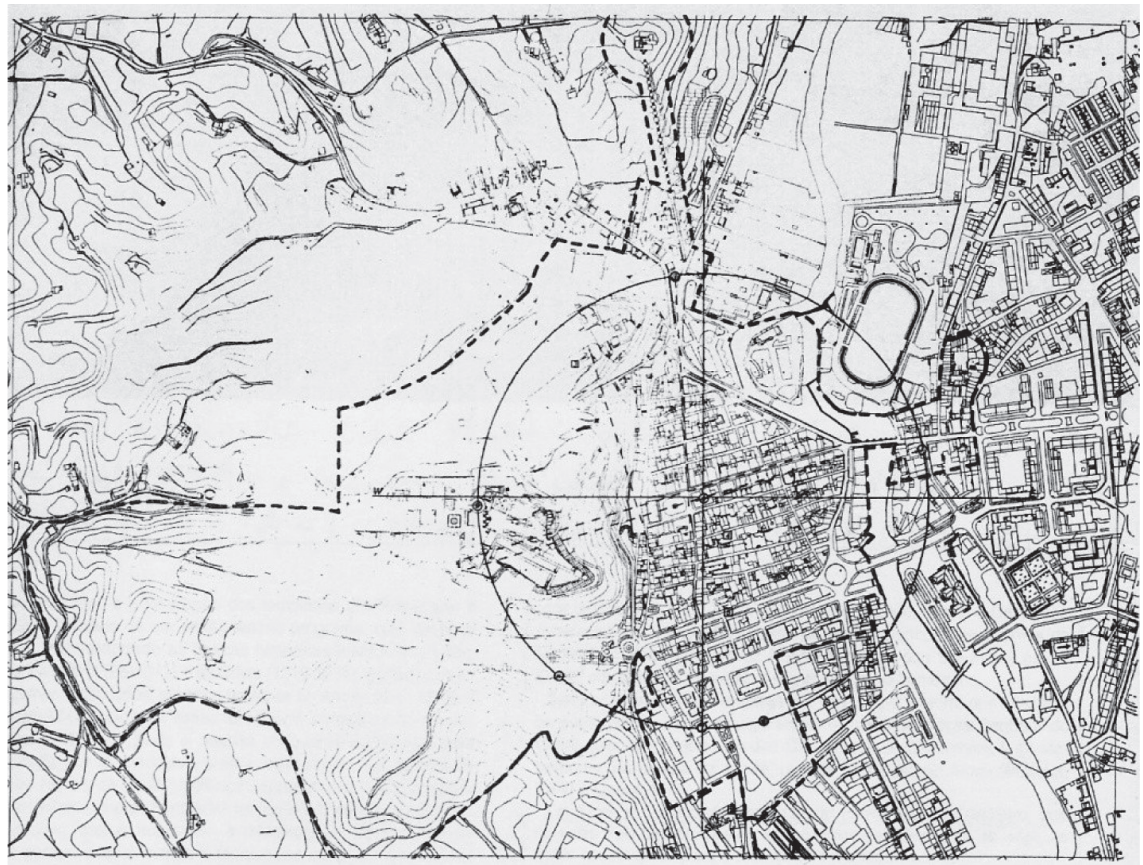

Fonte: Manuel Gandra (1996, p. 31). Circunferência que tem como centro a Igreja de São João Baptista traçada segundo Gandra por D. Gualdim Pais.

${ }^{25}$ GANDRA, Manuel J. - Da Nova Roma à Nova ou Celeste Jerusalém. Mafra: Centro de Ernesto Soares, [s.d.], p. 31. Segundo o mesmo autor, o Mestre "terá concluído a topografia lançando marcos para ulteriores edificações, destinando-lhe, eventualmente, as respectivas funções, (...) e foram escrupulosamente seguidos até ao século XVII'. Manuel J. Gandra Tomar e o Projecto Templário, Rotas do Sagrado in Circuitos Templários. [s.1], [s.d]. 
Se as diferenças dimensionais entre estas duas cidades são bastantes acentuadas, tal não ocorre se equipararmos o recorte das suas muralhas e certas particularidades da Charola com a Cúpula do Rochedo ${ }^{26}$, principalmente porque estes dois últimos, como já vimos, situam-se ambos sobre afloramentos rochosos, destacando-se na paisagem envolvente. Estes aspectos demonstram que o Mestre D. Gualdim Pais e os seus irmãos templários fizeram "transportar" Jerusalém - lugar onde a "terra está mais perto do céu" 27 - até à sua sede em Tomar. Toda esta leitura que acabamos de fazer temos de entendê-la, como é lógico, a partir das mentalidades espirituais surgidas na Idade Média, e tendo sempre em linha de conta que D. Gualdim Pais, futuro mestre do Templo em Portugal, esteve a combater na Palestina, onde conheceu a cidade de Jerusalém e a casa-mãe da Ordem.

${ }^{26}$ OLIVEIRA, Nuno Villamariz - Os Castelos da Ordem... cit., p. 216.

${ }^{27}$ NOVOA, Feliciano Portela - A Actividade Assistencial das Ordens Militares in MOVOA, Feliciano Portela e AYALA, Carlos Martins (ed.) - As Ordens Militares na Europa Medieval. Lisboa: Chaves Ferreira - Publicações, S. A., 2005, p. 197. 